\title{
Beta Risk Estimation In Stocks
}

Paraschos Maniatis, (Email: pman@ @sch.gr), Athens University of Economics and Business, Greece Nicholas Gioulbaxiotis, Alpha Bank, Greece

\section{INTRODUCTION}

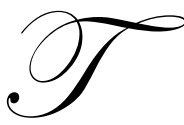

he purpose of this study is to estimate the Beta Risk Coefficient of 15 shares, which are included in the FTSE index. The risk evaluation when dealing with stocks is a very important factor, which should be taken into consideration from the inventor for the following reason: The profitability of a stock goes together with the risk of an adverse movement of the stock value. So, if the investor wants to plausibly expect high returns on his stock, he has to reckon with a high degree of risk. And inversely, high-risk stocks are the only ones promising high returns on the stock. This is the way, by which a stock exchange market works, and it cannot, by logical necessity, work in any other way. Now, given the closed positive relationship between high returns and high risk, the question rises whether the risk associated to a stock can be predicted, so that the investor is in a position to have an estimate of this undertaken risk. For this purpose various methods have been developed, some of them being of heuristic nature (technical analysis, evaluation of external information, study of the balancesheet of the company involved etc.), other being of probabilistic and/or of statistical nature. Between the latter we can mention the most popular ones, namely the market index model (or simply the market model) due to Sharpe (1963), which postulates a linear relationship between the return on a stock and the return on the market, and can be used to decompose total risk into diversifiable and non-diversifiable risk-components, and the capital asset pricing model (CAPM), which is rather a model of assets pricing, was developed by Sharpe (1963) and Lintner (1965).

This model is an equilibrium model of asset pricing, based explicitly on utility maximization and a given portfolio opportunity set, i.e. research of the way in which the supply of assets is balanced by the demand of assets. In our study we shall apply the market model. Our choice is based on two considerations: firstly, by its nature is more appropriate for the study of the stock risk, and secondly, it is much easier than the CAPM with no less explanatory power, at least for the purpose of our study. Nevertheless, it should be mentioned from the beginning that the use of the market model is not free of objections, pertaining to theoretical and empirical considerations. Besides the difficulties relating to all financial time series, it takes into consideration the general stock index only, neglecting other important parameters, such as the firm' size, price-earning ratios and dividend yield. Ross (1976) has analyzed the effect of these parameters on the occasion of his critique to the CAPM. However, we shall proceed with the application of the market model, bearing in mind the above mentioned advantages and disadvantages of the model. In the last part of this study, we shall try to critically assess the results of this application.

A modern approach of the problem is that of Brailsford, Faff and Oliver (1997), which highlights the difficulties of application of the CAPM in its practical application and implies the use of an empirical counterpart of the CAPM model, known as the 'market model'. The authors focus their critique in non-trivial problems appearing in selecting the model inputs, namely, the determination of the risk-free rate of interest, of an estimate of the expected return on the market portfolio and an estimation of the asset-specific 'beta' measure. Also, the authors point out the fact that the risk-free rate and expected return on the market portfolio are often based on historical estimates with some ad hoc adjustments The truth of the last assertion is solemnly manifested in the case of our data as it can be seen in the chapter devoted to the data discussion. Further, Brailsford, Faff and Oliver present the critique of Fama and French $(1992,1993,1996)$ over the empirical performance of beta, according to which the beta- among other weaknesses of the CAPM- has no ability to explain cross-sectional variation in equity returns. However, Brailsford, Faff and Oliver reckon that there exist arguments of retaining the beta concept, if not the CAPM itself, on the following grounds: Firstly, there is no credible theory-based model to replace the CAPM. Further, the Fama and French models include variables such as size and the book-to market of equity, which are more appropriate for 'data mining' than for econometric investigation. Secondly, that several counter pieces of evidence and arguments now exist which would caution against hasty abandonment of beta and the CAPM. In their argumentation the authors cite- among others- Black (1993a, 1993b), and Chan and Lakonishok (1993). Finally, 
Brailsford, Faff and Oliver adopt a version of CAPM, that of the 'market model', which they consider to be simply an expression of a statistical relationship and accessible for estimation of beta. This is, also, the version, which we are going to use in our study. More application details are given in the proper chapter (VII).

\section{METHODOLOGY}

For the investigation of the behavior of the Beta-Risk Coefficient we shall first try to acquire insight into our raw data using the methods of descriptive statistics, which is a necessary stage before any further statistical treatment of the data. This will enable us to appreciate the plausibility of the necessary assumptions for the application of methods of inferential statistics (normal distribution of the regression residuals, existence of autocorrelation in the time series, etc.). Then, equipped with the information acquired from the data description we shall proceed to the application of the proper statistical methods pertaining to our problem: analysis of the time series, in which our data consist, and regression analysis seeking to estimate for each share the parameters of the Beta Risk model and the coefficient of determination $\left(\mathrm{R}^{2}\right)$ between values of share and values of FTSE index. The idea is to estimate for each share the deviation of its movement from that of the FT all-share index and hence evaluate the risk hiding in the share. The tests of significance of the findings will enable us to conclude on the pertinence of applying regression methods for the estimation of the shares risk. Then, regardless of the results of the significance tests, we shall submit the data to a research consisting in application of multivariate statistical methods, namely that of Principal Components Analysis. We feel that the application of this method is necessary for two reasons: a/ The methods of inferential statistics are heavily loaded with restrictive assumptions, which are rarely met in problems of the kind we treat. Testing the validity of these assumptions with methods of inferential statistics requires even heavier assumptions... b/ The multivariate methods supply the researcher with a quick insight into the similarities and the correlations between the data (if, and in the measure that any exist), which in many cases is all that one can expect from the statistical approach of a problem. However, for the problem of estimating the beta risk estimation the regression techniques are indispensable and we shall use them transforming the data in a form appropriate to the treatment of stocks- namely, in the form $\operatorname{Ln}\left(\mathrm{p}_{\mathrm{t}} / \mathrm{p}_{\mathrm{t}-1}\right)$. Justification for this transformation shall be given in the Chapter VII concerning the regressions. Finally, we shall give our general conclusions on the whole exercise. Therefore, according to the above approach, the plan of the study is structured as follows:

- $\quad$ Graphical representation of the data descriptive statistics - Skewness and Kyrtosis analysis.

- $\quad$ Correlation analysis.

- Application of the Principal Components Analysis (CPA) as supplementary method for quick, simple, and comprehensive treatment of the data.

- Investigation for autocorrelation and trend in the time series.

- $\quad$ Definition of the model and regression analysis of the share values to the FT all-share index. Test for stability of the regression parameters.

- $\quad$ Conclusions.

\section{SOME NOTES ON THE DATA}

The available data consist of 1768 daily measurements for each share, for the FT all-share index and the Risk-Free rate. All measurements are simultaneous so that the calculations are comparable. The data cover the time period from 23/03/90 to 31/12/96 (i.e. 1768 daily measurements). We have chosen for each time series only the last 120 values (i.e. from 17/07/96 to 31/12/96). This choice can be justified by the following arguments:

- It was impossible for us to deal with such a bulk of information (17 x $1768=30056$ measurements!), given that the data were available in a text file form.

- Long time series for economic data, and especially for financial data, are not stable, in the sense that the structure underlying the data changes and the obtained results from application of any reasonable statistical method are, in the most of the cases, meaningless. Technically speaking, the time series is not stationary or it cannot be transformed to stationary by applying any common differencing method.

- The most recent measurements are probable to be more useful for our study, especially if we are interesting in extrapolations in the future. 
- $\quad$ The time span used covers almost the half of the year, so the values of the shares can be reasonably considered to reflect their yearly course. The series covers part of summer, autumn, and part of the winter.

- $\quad$ The use of daily values include all of the week (working) days, so the can be considered as unbiased, in respect to the week's day.

- $\quad$ Finally, 120 measurement are pretty enough for the application of the (simple) linear model.

The initial and the transformed data for the application of the market model, details of calculations and the graphs are shown in the appendix to the study. All calculations have been performed with the STATISTICA module of Windows.

\section{GRAPHICAL REPRESENTATION OF THE DATA-DESCRIPTIVE STATISTICS- SKEWNESS AND KYRTOSIS ANALYSIS}

The descriptive analysis of the data starts with the graphical representation of the data as time series. The graph GR1-Daily Values of the Shares exhibits the behavior of the time series during the 120 days in which the closing values of the shares are monitored, along with the values of the FTALLSH index. As we can see in the graph all shares exhibit a slight upward tendency, unless the shares of PSON, which after a long cycle returns to its initial values and the share SCHR which exhibits a steady increase. Also clear increase exhibits the FTALLSH index. Besides, the smooth form of the time series, accompanied with wavelets indicate existence of positive autocorrelation in the series. Details of autocorrelation in the time series will be given in Chapter VI. We can also see in the graph that the time series are not synchronized either with each other or with the FTALLSH index. This explains the poor coefficients of correlation between the variables. This luck of synchronization will clearly appear in the scatter plots of the regression of the share values to the value of FTALLSH.

As mentioned above, the data consist of 120 daily measurements for 15 shares, for the FT all-share index and the RiskFree rate. The raw data- names and values of the shares can be seen in the table G0-Initial Data. The table G1- Detailed statistics of Initial Data and Descriptive Statistics exhibits for each variable the most important statistics as mean, standard deviation, median, range, skewness, kyrtosis, etc. We comment these statistics as follows:

- The means of the time series are clearly exhibiting differences between each other, which suggests the idea that the series are fluctuating at different levels. This can also be realized from the graphical representation of the time series (Graph GR1).

- $\quad$ On the other side, the standard deviations, defined as:

Variation $=$ Standard Deviation $/$ Mean

have considerably small values, which implies that the time series have pretty small variation. This conclusion is re-enforced by the small range of values fluctuation, as obtained by the difference between maximum and minimum values of the measurements (graph GR2).

- $\quad$ The median of each time series is very close to its mean, which advocates for symmetry in the frequency distributions.

- $\quad$ The skewness of a distribution is given by the formula:

Skewness $=\mu_{3} / \mathrm{s}^{3}$

where $\mu_{3}$ is the third central moment and s the standard deviation of the distribution. As shown in the table, some distributions exhibit positive and some negative skewness. The number of frequency distributions with positive skewness is almost equal to that of negative. The highest (positive) skewness is shown in the frequency distribution of the share $\mathrm{ABF}(1.25)$ and the greatest negative, in absolute value, skewness is that of the FTALLSH (-0.99), which is not important, given that the maximum positive skewness, which can appear is of measure 2 (that of the exponential distribution). For all the rest frequency distributions the skewness are at very small, indicating that the frequency distributions are close to the symmetry. This result 
was already obtained in Chapter I from the closeness of all means of the variables to their corresponding medians. In order for us to have an insight in the skewness of the distributions we give the graphs of the distribution with the greatest (in absolute value) negative skewness (GR9), that of the greatest positive skewness (GR10) and that with skewness closest to zero (GR11). However, as it can easily be seen in the last distribution, it is bimodal and this advocates that the distribution is a mixture of two parent populations.

- $\quad$ The kurtosis of a frequency distribution is given by the formula:

Kurtosis $=\mu_{4} / \mathrm{s}^{4}$

where $\mu_{4}$ is the forth central moment and $\mathrm{s}$ the standard deviation of the distribution. The normal distribution has a Kurtosis of 3 and this is consequently taken as a standard of comparison; distributions with a kurtosis greater than of 3 are described as leptokurtic and distributions with a kurtosis less than 3 as leptokurtic. By virtue of this remark it is plausible not to use the above formula for the kurtosis but the equivalent form:

Kurtosis $=\left(\mu^{4} / \mathrm{s}^{4}\right)-3$

Therefore, the kurtosis of each frequency distribution is calculated as the algebraic deviation of the kurtosis from the standard value 3 (that of the normal distribution). Hence, a positive value of kurtosis denotes a leptokurtic distribution, while a negative value denotes a platykurtic one. Under this notation it is noticeable that almost all frequency distributions are platykurtic, with the exception of the frequency distributions of the share ABF and the FTALLSH. The kurtosis of each frequency distribution is shown in column 10 of the table G3.

The above considerations concerning skewness and kurtosis of the distributions, could give us some advance information pertaining to the probabilisation of the behavior of the shares: their behavior doesn't exhibit patterns quite close to normal distribution, which calls for attention when applying parametric methods, as that of the least squares, for the estimation of the beta risk coefficient.

\section{CORRELATION ANALYSIS}

For the correlation analysis we have used the Pearson's coefficient of correlation:

$\mathrm{r}=\operatorname{Cov}(\mathrm{Y}, \mathrm{x}) /[\operatorname{StDev}(\mathrm{Y}) * \operatorname{StDev}(\mathrm{x})]$

The correlations (coefficients of correlation) between the 15 returns on equity, the risk-free rate and the FTALLSH index are shown in the table G2-Correlations between the 17 variables. We comment the table as follows:

- The most shares are poorly correlated between each other, with the exceptions of the correlations between (we mention correlations equal or greater than 0.65 ):
ABF / LAND (0.77)
ABF / SEBE (0.77)
ALLD / RCOL (0.69)
BTR / TOMK (0.71)
GKN / RCOL (0.69)
LAND / PSON (0.84)
PSON / SCHR (0.66)
SCHR / SEBE (0.71)
SCTN / STAN (0.75) 
- The most shares are positively correlated. When there exist a negative correlation, the value of the coefficient of correlation is very small (The highest in absolute value is between ASDA / TOMK (-0.67). This is not a surprising result since all shares exhibit an upward overall tendency.

- So far as the correlation of the shares with the FTALLSH index is concerned, the latter exhibits strong correlation with ABF (0.67), LAND (0.91), PSON (0.78), SCHR (0.84) and SEBE (0.75). Again here we have considered only coefficients of correlation greater than 0.65 . The correlation of the shares index with the rest of the shares is poor. It is interesting that no share is negatively correlated with FTALLSH.

- $\quad$ The Risk-Free rate is strongly correlated only with the share ABF (0.87). It is interesting that this variable is evenly correlated both negatively and positively, although poorly, with the rest of the shares.

- $\quad$ The searching into the correlation matrix was tedious and time consuming even in the present case of a relatively small number of variables involved. Besides one cannot have a general insight in the correlation values. This kind of analysis of correlations becomes impossible when the number of variables is great (say, 30). Equally good, or even better results can be obtained by using the method of Principal Components Analysis. This will be undertaken in Chapter V.

\section{APPLICATION OF THE PRINCIPAL COMPONENTS ANALYSIS (CPA)}

On purpose we have left in the end of our study the treatment of the data according to the technique of Principal Components. This technique belongs to the family of the factorial or multidimensional descriptive techniques (Principal Components Analysis, Multidimensional Discriminant Analysis, Factor Analysis, Canonical Analysis and Correspondences Analysis, to mention only a few of them). The use of such techniques is not so popular and, besides, they present difficulties in interpreting the results in the factorial plane. However, the nature of our data calls for the use of the Principal Components Analysis and we shall apply the method as a complementary or even alternative approach to the regression technique. We have used the mean-corrected and standardized version of the method, for the share/variables are of considerable different levels of magnitude.

We proceeded fist to the application of the method to the 15 shares, leaving out of consideration the FTALLSH index and the Risk-Free rate so that to study the structure and relationships of the shares between each other. The results are presented in the graph GR6- Extraction: Principal components (analysis of the 15 shares). We do not give details of the interpretation of the results, for this would require a special study. We mention only the most important points:

- $\quad$ The total explained variance from the factorial axes is $60,5 \%$ of the total variance in the data. So the results are in a high extent reliable.

- $\quad$ The shares are clearly forming three distinct groups (clouds). The shares participating in one group have similar correlations with the factorial axes (similar loadings in the PCA terminology), that is, they are correlated more with each other than with the shares belonging to the other groups. The ASDA share stays alone.

- $\quad$ The variables belonging to the same cloud similar profiles, that is, they are quite proportional. The closer the distance between two shares, the stronger is their similarity.

- $\quad$ The shares close to a factorial axis and remote from the origin exhibits strong correlation with the factorial axis, i.e. with the rest of the shares.

The exercise is repeated, but this time with in inclusion of the FTALLSH index and the Risk-Free variables. The results are shown in the graph GR7-Extraction: Principal components (analysis of the 15 shares + Ftallsh + RiskFree). The lines of the interpretation of the graph are similar to the ones exposed in the previous analysis of the 15 shares. We only point out the comfortable visual acquisition of the content of the correlations matrix as shown in table G2. This is one of the merits of the Principal Components technique.

Finally in the graph GR8-Factor scores are shown the factor scores, that is, the positions of the shares profiles with respect to the factorial axes and to each other. The numbers in the factorial plan correspond to the 120 days in which the closing values of the shares were monitored. Here again, the proximity between two numbers 
denotes similarity of the behavior of the shares in these two days. It is clear from the systematic sequential pattern of the numbers that there exist autocorrelation in the time series.

\section{INVESTIGATION FOR AUTOCORRELATION AND TREND IN THE TIME SERIES}

Special attention was given to the detection of autocorrelation in the time series. The existence of autocorrelation is important for the application of the method of the Least squares: when the values of the depended variable exhibit autocorrelation, it means that the residuals in the structural model are auto-correlated, which violates the conditions of application of the Least squares method. This method explicit requires that the residuals be uncorrelated stochastic variables, following the normal distribution-hence independent stochastic variables. Of course one can use the Least Squares method under any conditions, but in this case one cannot apply the usual procedures for testing the significance of the estimated parameters of the model (for example the student t-test of non-nullity of each isolated parameter or the Fisher F-test for simultaneous non-nullity of the parameters and the non-nullity of the coefficient of correlation between the realized values of the depended variable and the theoretical values obtained from the least squares regression. In our case, all time series of the 15 shares and the FTALLSH index exhibit positive autocorrelation. This was expected since it is known from the theory and the practice of the financial time series that the daily (closing) value of a share is not independent from its value of the previous day(s). We give details of the treatment of the time series for existence of autocorrelation only in the case of one time series, namely that of the FTALLSH index. The graph GR1 shows that the FTALLSH index exhibits a steady upward movement, which excludes the possibility that the time series is stationary, since stationary time series are characterized by constancy of the mean for every segment of the series. Further, as we can see in the graph G3Autocorrelation Function, there exist trend in the series. Finalizing the autocorrelation analysis of the time series it would be not useless to mention that a simpler way to detect autocorrelation in the time series could be the plotting of each value of the time series against the value of the previous day. We have done so for the FTALLSH index and as we can see in graph GR5-Plotting Ftallsh against Ftallsh-1 the obtained points are almost collinear. The value of the regression coefficient is $0,956-$ a value very near to 1 . Therefore, given the existence of autocorrelation and trend in the time series, we submitted the initial data to the transformation $\operatorname{Ln}\left(\mathrm{p}_{\mathrm{t}} / \mathrm{p}_{\mathrm{t}-1}\right)$, which is the usual one for the regression between share values.

\section{DEFINITION OF THE MODEL AND REGRESSION ANALYSIS OF THE SHARE VALUES TO FT- ALLSHARE INDEX. TEST FOR STABILITY OF THE REGRESSION PARAMETERS}

This chapter includes the main task of our study, the estimation of the Beta Risk Coefficient in the market model. As guideline for the theorization of the model, the definition of the variables, the data organization, the index adjustments, the sampling interval, and the treatment of outliers we have followed as close as possible the work of Brailsford, Faff and Oliver (1997). For the robustness of the beta coefficient over time we took advice from the articles of Brooks, Faff and Lee (1992) and Collins, Ledolter and Rayburn (1987). For the seasonality analysis we have employed method of the time series analysis (spectral analysis). However, we have abstained of considering omitted variables, as indicated by the aforementioned authors, for two reasons: Firstly, to search through effects of omitted variables would charge unevenly the statistical approach of the study without adding to the model much additional information and predicting power and, secondly, the inclusion in the model of variables such as size, type of ownership etc. would require use of dummy variables, which would transform our problem into a problem of analysis of variance and analysis of covariance, which is far beyond the scope and the limits of our study. Besides, Handa, Kothari and Wesley (1989) indicate that size-effect tests using daily or monthly betas differ from the betas estimated from longer-interval returns. For the purpose of our study we have adopted the simple version of the market model:

$\mathrm{Y}_{\mathrm{t}}=\mathrm{a}+\mathrm{bx}_{\mathrm{t}}+\mathrm{E}_{\mathrm{t}} \quad(\mathrm{t}=1,2, \ldots \ldots \ldots . \mathrm{T})$ 
where:

$\mathrm{Y}_{\mathrm{t}}=$ Transformed share value at close of the market in day $\mathrm{t}$

$\mathrm{x}_{\mathrm{t}}=$ Transformed FT All-Share index in day $\mathrm{t}$

$\mathrm{E}_{\mathrm{t}}=$ Regression residual (error) in day $\mathrm{t}$

$\mathrm{a}=$ The intercept of the model

$\mathrm{b}=$ The linear regression coefficient of the model (the beta coefficient for our data).

As mentioned in the introduction and in the chapter for autocorrelation investigation the data have been submitted to the transformation $\mathrm{p}_{\mathrm{t}}-->\operatorname{Ln}\left(\mathrm{p}_{\mathrm{t}} / \mathrm{p}_{\mathrm{t}-1}\right)$, where $\mathrm{Ln}$ means the natural logarithm of the fraction in the parenthesis. The reason for this type of transformation is that since the time series are not stationary one way to perform regressions between the variables is to consider not the values of the variables but their change rates $\left(\Delta \mathrm{p}_{\mathrm{t}}\right.$ $\left.{ }_{1} / \mathrm{p}_{\mathrm{t}-1}\right)$. But,

$\operatorname{Ln}\left(\mathrm{p}_{\mathrm{t}} / \mathrm{p}_{\mathrm{t}-1}\right)=\operatorname{Ln}\left[\left(\mathrm{p}_{\mathrm{t}-1}+\Delta \mathrm{p}_{\mathrm{t}-1}\right) / \mathrm{p}_{\mathrm{t}-1}\right]=\operatorname{Ln}\left[1+\left(\Delta \mathrm{p}_{\mathrm{t}-1} / \mathrm{p}_{\mathrm{t}-1}\right)\right]$

which, for small values of $\Delta \mathrm{p}_{\mathrm{t}-1}$ is approximately equal to $\Delta \mathrm{p}_{\mathrm{t}-1} / \mathrm{p}_{\mathrm{t}-1}$, that is the change rate of the variable. For the estimation we have used for each share the method of the Ordinary Least Squares. Hence, the estimates of the parameters and the coefficients of determination were obtained from the well-known formulas of the Least squares method:

$\begin{array}{ll}\text { Beta estimate: } & \mathrm{b}=\operatorname{Cov}(\mathrm{Y}, \mathrm{x}) / \operatorname{Var}(\mathrm{x}) \\ \text { Intercept: } & \mathrm{a}=\operatorname{Mean}(\mathrm{Y})-[\mathrm{b} * \operatorname{Mean}(\mathrm{x})] \\ \text { Coefficient of determination: } & \mathrm{R}^{2}=\left[\operatorname{Cov}(\hat{\mathrm{Y}}, \mathrm{Y}) /[\operatorname{StDev}(\hat{\mathrm{Y}}) * \operatorname{StDev}(\mathrm{Y})]^{2}\right. \\ \text { Adjusted } \mathrm{R}^{2}: & \operatorname{Adj}^{2}=1-\left(1-\mathrm{R}^{2}\right) *(\mathrm{n}-1 / \mathrm{n}-\mathrm{p}) \text { with } \mathrm{p}=2 \text { degrees of freedom. }\end{array}$

In order to test the stability of the model's parameters we have applied the split-half test, that is the 119 values have been split into two groups of 60 (left-tail values) and 59 (right-tail values) accordingly, and then the regression was performed separately for each group. In the following Table 1 are exhibited the estimates of the model's parameters for each regression.

From the above table we conclude that out of the 17 sets of regression only in 7 the beta coefficients are closed to each other in all three sets (the bolt highlighted ones). However this stability should be carefully interpreted: the regression is not applied on the initial values but on the transformed ones, and the (hidden) form of the model (1) in its rigorous form is dy/ydt $=a+b^{*}(d x / x d x)$, the solution of which is of the exponential form $y=$ $\mathrm{Cx}^{\mathrm{b}}$. Therefore, small differences of b's might mean great difference in the y's behaviour. So, although the beta of the shares ASDA, PSON, SCHR, SCTN, SEBE, STAN and UNWS exhibit a relative stability, stability of their connection with the Ft-all-shares index is limited. This could be additional evidence that the movements of shares do not follow in a systematic, uniform manner the movements of the overall index FTALLSH index. The practical conclusion of the matter is that the classification of the shares as high-risk and low-risk might be doubtful. 
Table 1: Parameters Of The Regression Model (1)

\begin{tabular}{|c|c|c|c|c|c|}
\hline & & & $\begin{array}{c}\text { All 119 } \\
\text { values }\end{array}$ & $\begin{array}{c}60 \\
\text { left-tail values }\end{array}$ & $\begin{array}{c}59 \\
\text { right-tail values }\end{array}$ \\
\hline 1 & $\mathrm{ABF}$ & $\begin{array}{c}a= \\
b= \\
\operatorname{Adj}^{2}\end{array}$ & $\begin{array}{l}0.0012 \\
0.5189 \\
0.1140\end{array}$ & $\begin{array}{l}0.0001 \\
0.5029 \\
0.1019\end{array}$ & $\begin{array}{l}0.0012 \\
0.1838 \\
0.1205\end{array}$ \\
\hline 2 & ALLD & $\begin{array}{c}a= \\
b= \\
\operatorname{Adj}^{2}\end{array}$ & $\begin{array}{l}0.0000 \\
0.5872 \\
0.0511\end{array}$ & $\begin{array}{l}0.0009 \\
1.1012 \\
0.1770 \\
\end{array}$ & $\begin{array}{l}0.0004 \\
0.3645 \\
0.0063 \\
\end{array}$ \\
\hline 3 & ASDA & $\begin{array}{c}a= \\
b= \\
\operatorname{Adj}^{2}\end{array}$ & $\begin{array}{l}0.0000 \\
0.5553 \\
0.0533 \\
\end{array}$ & $\begin{array}{c}-0.0017 \\
0.7072 \\
0.0322 \\
\end{array}$ & $\begin{array}{l}0.0017 \\
0.5224 \\
0.0871 \\
\end{array}$ \\
\hline 4 & BTR & $\begin{array}{c}a= \\
b= \\
\operatorname{AdjR}^{2}\end{array}$ & $\begin{array}{l}0.0007 \\
0.7674 \\
0.0771\end{array}$ & $\begin{array}{l}0.0004 \\
0.3813 \\
0.1279 \\
\end{array}$ & $\begin{array}{l}0.0006 \\
0.5771 \\
0.0419 \\
\end{array}$ \\
\hline 5 & GKN & $\begin{array}{c}a= \\
b= \\
\operatorname{AdjR}^{2}\end{array}$ & $\begin{array}{c}-0.0008 \\
0.7203 \\
0.1398\end{array}$ & $\begin{array}{l}0.0004 \\
0.9654 \\
0.2501 \\
\end{array}$ & $\begin{array}{c}-0.0231 \\
0.5774 \\
0.0824\end{array}$ \\
\hline 6 & KGF & $\begin{array}{c}a= \\
b= \\
\operatorname{AdjR}^{2}\end{array}$ & $\begin{array}{c}-0.0001 \\
0.5375 \\
0.0731\end{array}$ & $\begin{array}{c}-0.0005 \\
1.0761 \\
0.1994\end{array}$ & $\begin{array}{c}-0.0003 \\
0.2893 \\
0.0134\end{array}$ \\
\hline 7 & LAND & $\begin{array}{c}a= \\
b= \\
\operatorname{AdjR}^{2}\end{array}$ & $\begin{array}{l}0.0011 \\
0.5856 \\
0.1624\end{array}$ & $\begin{array}{l}0.0009 \\
1.1172 \\
0.3015 \\
\end{array}$ & $\begin{array}{l}0.0007 \\
0.3369 \\
0.0838 \\
\end{array}$ \\
\hline 8 & PSON & $\begin{array}{c}a= \\
b= \\
\operatorname{AdjR}^{2}\end{array}$ & $\begin{array}{l}0.0006 \\
0.9369 \\
0.1374\end{array}$ & $\begin{array}{c}-0.0000 \\
1.10992 \\
0.1308\end{array}$ & $\begin{array}{l}0.0011 \\
0.8742 \\
0.1340 \\
\end{array}$ \\
\hline 9 & RCOL & $\begin{array}{c}a= \\
b= \\
\operatorname{AdjR}^{2}\end{array}$ & $\begin{array}{c}-0.0002 \\
0.6850 \\
0.1251\end{array}$ & $\begin{array}{l}0.0005 \\
0.9445 \\
0.1952 \\
\end{array}$ & $\begin{array}{c}-0.0012 \\
0.5452 \\
0.0782\end{array}$ \\
\hline 10 & SCHR & $\begin{array}{c}a= \\
b= \\
\operatorname{AdjR}^{2}\end{array}$ & $\begin{array}{l}0.0005 \\
0.8766 \\
0.1810\end{array}$ & $\begin{array}{l}0.0016 \\
0.9025 \\
0.0828 \\
\end{array}$ & $\begin{array}{l}0.0007 \\
0.8701 \\
0.3236 \\
\end{array}$ \\
\hline 11 & SCTN & $\begin{array}{c}a= \\
b= \\
\operatorname{AdjR}^{2}\end{array}$ & $\begin{array}{c}-0.0000 \\
0.6042 \\
0.1392\end{array}$ & $\begin{array}{c}-0.0010 \\
0.7206 \\
0.1743\end{array}$ & $\begin{array}{l}0.0007 \\
0.5698 \\
0.1210 \\
\end{array}$ \\
\hline 12 & SEBE & $\begin{array}{c}a= \\
b= \\
\operatorname{AdjR}^{2}\end{array}$ & $\begin{array}{l}0.0008 \\
0.5657 \\
0.1288\end{array}$ & $\begin{array}{l}0.0000 \\
0.5739 \\
0.1015\end{array}$ & $\begin{array}{l}0.0016 \\
0.5785 \\
0.1407\end{array}$ \\
\hline 13 & STAN & $\begin{array}{c}a= \\
b= \\
\operatorname{AdjR}^{2}\end{array}$ & $\begin{array}{l}0.0001 \\
0.8521 \\
0.1268\end{array}$ & $\begin{array}{c}-0.0001 \\
0.9521 \\
0.1093\end{array}$ & $\begin{array}{l}0.0002 \\
0.8106 \\
0.1271\end{array}$ \\
\hline 14 & TOMK & $\begin{array}{c}a= \\
b= \\
\operatorname{AdjR}^{2}\end{array}$ & $\begin{array}{c}-0.0004 \\
1.0839 \\
0.1566\end{array}$ & $\begin{array}{c}-0.0008 \\
1.7589 \\
0.2609\end{array}$ & $\begin{array}{c}-0.0009 \\
0.7703 \\
0.0954\end{array}$ \\
\hline 15 & UNWS & $\begin{array}{c}a= \\
b= \\
\operatorname{Adj}^{2}\end{array}$ & $\begin{array}{l}0.0001 \\
0.9055 \\
0.1416 \\
\end{array}$ & $\begin{array}{c}-0.0001 \\
1.0579 \\
0.1274 \\
\end{array}$ & $\begin{array}{l}0.0003 \\
0.8403 \\
0.1418 \\
\end{array}$ \\
\hline 17 & RISKFR & $\begin{array}{c}a= \\
b= \\
\operatorname{AdjR}^{2}\end{array}$ & $\begin{array}{c}0.0011 \\
-0.2845 \\
0.0157\end{array}$ & $\begin{array}{c}0.0004 \\
-0.0860 \\
-0.0031\end{array}$ & $\begin{array}{c}0.0016 \\
-0.3636 \\
0.0114\end{array}$ \\
\hline
\end{tabular}




\section{CONCLUSIONS}

Reverting to the results of the part VII of our study pertaining to the regression of the share values to the general stock index and some of its weaknesses as mentioned in the introduction, we would like to express some thoughts on the use of the market model relating to its explanatory and predictability power. From the financialtheoretical point of view the model cannot be considered but as incomplete. It leaves out of consideration important parameters in the risk assessment of a stock such as the firm's size, the price-earnings ratio, the dividend policy of the firm, its part and perspectives. Further, even in the remote possibility that the stock's value is fully associated in the statistical sense to the value of the general stocks index, nothing can assure that this general index do not dramatically drops, due to a stock exchange Crash, or to a recession of the branch of the stock (High-Tech stocks in the New York Stock Exchange) or of the whole economy. In this sense the beta-risk coefficient is only of relative value, not being able to estimate the risk of the stock from all sources of uncertainty. Now, as far as its predictability power is concerned, although the estimates of the beta-coefficient were found in the most of the stocks significant, the values of the corresponding $\mathrm{R}^{2}$ are so small (although statistically significant) that the model is deprived from predictability power, even in the relative sense. We feel that the results obtained from the application of the market model are not satisfactory compared with the posed target of the study. It is self-explanatory that better application of the market model, more extensive research on the subject with more refined statistical techniques can exhibit better results. However, we believe that inclusion of much more variables in the model and elaboration with multivariate statistical methods will give much better results. The size of the available data and the power of the multivariate methods can permit this approach in the lines exposed in part V.

\section{BIBLIOGRAPHY}

1. Aivazian, S. 1970, Etude Statistique des Dependences, Moscow: Mir Publishers.

2. Arkin, H. and Colton R. 1964, Statistical Methods, New York: Barnes \& Noble.

3. Aunon J. and Chandrasekar V. 1998, Introduction to Probability and Random Processes, New York: McGraw-Hill.

4. $\quad$ Black, F. 1993b, Beta and Return, Financial Analysis Journal, vol.48, pp. 36-8.

5. $\quad$ Black, F. 1993a, Beta and Return, Journal of Portfolio Management, vol.20, pp. 8- 18.

6. Blake, D. 1990, Financial Market Analysis, London: McGraw-Hill.

7. Blume, M. 1975, Betas and the Regression Tendencies, Journal of Finance, vol. 30, pp. 785-95.

8. Bouroche, J. M. and Saporta G. 1975, L' Analyse des Donnees, Paris: Presses Universitaires De France.

9. Brailsford, T., Faff, R., and Oliver, B. 1997, Research Design Issues in the Estimation of Beta, McGrawHill series in advanced finance.

10. Brailsford, T. 1995, An Empirical Test of the Effect of the Return Interval on Conditional Volatility, Applied Economic Letters, vol. 2, pp 156-8.

11. Brailsford, T. and Davis, K. 1995, Valuation with Imputation, JASSA, pp.14-18.

12. Brailsford, T. and Faff, R. 1993, Modelling Australian Stock Market Volatility, Australian Journal of Management, vol. 18, pp. 109-32.

13. Brailsford, T. and Josev, T. 1997, The Impact of the Return Interval on the Estimation of Systematic Risk in Australia, Pacific-basin Finance Journal.

14. Brealey, R. A. and Myers, S. C. 1991, Principles of Corporate Finance, New York: McGraw-Hill.

15. Brooks, R., Faff, R. and Lee, J. 1992, The Form of Time Variation of Systematic Risk: Some Australian Evidence, Applied Financial Economics, vol. 2, pp. 191-8.

16. Chan, L. and Lakonishok, J. 1993, Are Reports of Beta's Death Premature?, Journal of Portfolio Management, vol. 19, pp. 51-62.

17. Chatfield, C. 1996, The Analysis of Time Series, London: Chapman \& Hall.

18. Collins, D., Ledolter, J., and Rayburn, J. 1987, Some Further Evidence on the Stochastic Properties of Systematic Risk, Journal of Business, vol. 60, pp. 425-48.

19. Corhay, A. 1992, The Intervaling-Effect Bias in Beta; A Note, Journal of Banking and Finance, vol. 16, pp. 61-73.

20. Davies, D. 1992, The Art of Managing Finance, London: McGraw-Hill. 
21. Dimson, E. 1979, Risk Measurment When shares are Subject to Infrequent Trading, Journal of Financial Economics, vol. 7, pp. 197-226.

22. Draper, P. and Paudyal, K. 1995, Empirical Irregularities in the Estimation of Beta: The Impact of Alternative Estimation Assumptions and Procedures, Journal of Business Finance and Accounting, vol. 22, pp. 157-77.

23. Efimov A. V. (Ed) 1988, Random Functions In Higher Mathematics Part 3, Moscow: Mir Publishers.

24. Fabozzi, F. and Francis, J. 1977, Stability Tests for Alphas and Betas over Bull and Bear Market Conditions, Journal of Finance, vol. 32, pp. 1093-9.

25. Fabozzi, F. and Francis, J. 1979, Mutual Fund Systematic Risk for Bull and Bear Markets, Journal of Finance, vol. 34, pp. 1243-50.

26. Faff, R. 1992, Capital market Anomalies: A Survey on the Evidence, Accounting Research Journal, vol. 5, pp.3-22.

27. Faff, R., Lee, J., and Fry, T. 1992, Time Stationarity of Systematic Risk: Some Australian Evidence, Journal of Business Finance and Accounting, vol. 19, pp. 253-70.

28. Fama, E. 1976, Foundations of Finance, Basic Books Inc, New York.

29. Fama, E. and French, K. 1992, The Cross-section of Expected Returns, Journal of Finance, vol. 47, pp. 427-65.

30. Fama, E and French, K. 1993, Common Risk Factors in the Returns on Stocks and Bonds, Journal of Financial Economics, vol. 33, pp. 3-56.

31. Fama, E. and French, K. 1996, Multifactor Explanations of Asset Pricing Anomalies, Journal of Finance, vol. 51, pp. 55-84.

32. Handa, P., Kothari, S., and Wasley, C. 1989, The Relation Between the Return Interval and Betas: Implications for the Size Effect, Journal of Financial Economics, vol. 23, pp. 79-100.

33. Hawawini, G. 1983, Why Beta Shifts as the Return Interval Changes, Financial Analysis Journal, vol. 39, pp. 73-7.

34. Huang, D. S. 1969, Regression and Econometric Methods, New York: John Wiley \& Sons.

35. Johnson, R. A. and Wichern D. W. 1998, Applied Multivariate Statistical Analysis, New Jersey: Prentice Hall.

36. Lebart L. and Fenelon J. P. 1973, Statistique et Infirmatique Aplliquees, Paris: Dunod.

37. Lehn, J. and Wegmann, H. 1992, Einfuerung in die Statistik, Stuttgart: Teubner.

38. Lintner, J. 1986, The valuation of Risk Assets and the Selection of Risky Investments in Stock portfolios and Capital Budgets, Review of Economics and Statistics, February.

39. McInish, T. and Wood, R. 1986, Adjusting for Beta Bias: An Assessment of Alternative Techniques: A Note, Journal of Finance, vol. 41, pp. 277-86.

40. Murray, L. 1995, An Examination of Beta Estimation Using Daily Irish Data, Journal of Business Finance and Accounting, vol. 22, pp. 893-906.

41. Ross, S. A. 1976, The Arbitrage Theory of Capital Asset Pricing, Journal of Economic Theory, December.

42. Scholes, M. and Williams, J. 1977, Estimating Betas from Non-synchronous Data, Journal of Financial Economics, vol. 5, pp. 309-27.

43. Sharpe, W. F. 1963, A Simplified Model for Portfolio Analysis, Management Science, January.

44. Theil, H. 1970, Principles of Econometrics, New York: John Wiley \& Sons.

45. Ventsel, H. 1973, Theorie des Probabilites, Moscow: Mir Publishers. 